\title{
KAJIAN PENERAPAN VISKOSITAS MINYAK PELUMAS PADA MESIN PENGGERAK UTAMA KAPAL PERIKANAN DI PT. HASIL LAUT SEJATI
}

\section{STUDY OF THE IMPLEMENTATION OF THE VISCOSITY OF LUBRICATION OIL IN THE FISHERING MAIN MOVEMENT MACHINE IN PT. HASIL LAUT SEJATI}

\author{
M. Subroto Alirejo, I Ketut Daging, Martin, Basino* dan Juniawan Preston Siahaan \\ Permesinan Perikanan, Sekolah Tinggi Perikanan Jakarta 12520, Indonesia \\ * Korespondesi Penulis: basino@kkp.go.id
}

Diterima: 1 November 2018; diterima setelah perbaikan: 7 November 2018; Disetujui: 12 November 2018

\begin{abstract}
ABSTRAK
Pelumas merupakan salah satu bahan yang penting dalam pengoperasian mesin kapal agar bekerja secara optimal, dan memberikan pelumas yang salah dapat mengakibatkan mesin mengalami kerusakan. Sedangkan Viskositas (Viscosity), adalah suatu angka yang menyatakan besarnya perlawanan/hambatan dari suatu bahan cair untuk mengalir atau ukuran besarnya tahanan geser dari bahan cair. Tujuan dari analisis sampel pelumas (Shell Rimula R4X 15W 40) di laboratorium ini adalah untuk mengetahui kondisi pelumas dan penyebab viskositas pelumas turun dari dua sampel pelumas (oli baru dan oli setelah tergunakan dengan jam kerja pelumas 312 jam).Hasil dari analisa sampel pelumas di laboratorium ini menunjukan bahwa kondisi dari dua sampel pelumas tidak normal. Dilihat dari uji fisik viskositas uji nilai di oli baru 11.33 seharusnya pada oli normal uji fisik Viskositas $100^{\circ} \mathrm{C}$ uji nilai 14.7 . Uji nilai TBN 17.1. Uji nilai Oksidasi 0.56 apabila oli baru seharusnya nilai Oksidasi 0 karena belum mengalami proses operasi mesin, indikasi oli baru itu adalah oli bekas, atau indikasi oli palsu. Dilihat dari uji fisik Viskositas uji nilai di oli setelah tergunakan 11.00, terindikasi mesin yang Overheat, karena tercampurnya bahan bakar, dilihat bahan bakar dengan Destilasi uji nilai 0.5 adanya kebocoran bahan bakar. Uji nilai TBN 15.03, normal karena TBN menetralisir asam sulfur di bahan bakar. Jadi hasil pengujian sampel pelumas merk Shell Rimula R4X 15W 40 olibaru dan oli setelah digunakan mengalami penurunan nilai viskositas.
\end{abstract}

Kata kunci: Analisis, Sampel, Viskositas, Minyak Pelumas, Mesin Utama.

\section{ABSTRACT}

Lubrication is a basic tool of the machine to work optimally, and providing the wrong lubricant can result in the engine being damaged. While Viscosity (Viscosity), is a number which states the amount of resistance / resistance of a liquid material to flow or the size of the shear resistance of the liquid material. The purpose of lubricant sample analysis (Shell Rimula R4X 15W 40) in this laboratory is to know the condition of the lubricant and the cause of the lubricant viscosity down from two lubricant samples (new oil and oil after use with 312 hours of lubricant working hours). The results of the lubricant sample analysis in this laboratory show that the condition of two lubricant samples is not normal. Seen from the physical test of the test value viscosity in the new oil 11.33 should be on the normal oil physical test Viscosity $100{ }^{\circ} \mathrm{C}$ test value 14.7. Test TBN value of 15.03, normal because TBN neutralizes sulfuric acid in fuel. So the result of testing of Shell Rimula R4X 15W brand lubricant samples of new oil and oil after use has decreased the value of viscosity.

Keywords: Analysis, Sample, Viscosity, Lubricating Oil, Main Engine.

Copyright (C) JKPT Juni 2018

Kajian Penerapan Viskositas Minyak Pelumas ........Alirejo, et.al 


\section{PENDAHULUAN}

Indonesia sebagai negara maritim memiliki coastal line yang hampir seperlima panjang pantai dunia sehingga memiliki potensi perikanan dan kelautan yang cukup besar. Indonesia juga dikenal kaya dengan marine diversity dimana lebih 450 spesies coral dan lebih dari 2.000 spesies ikan di wilayah perairan Indonesia. Tempat penelitian di PT. Hasil Laut Sejati yang berlokasi di Tanjung Balai Asahan Provinsi Sumatera Utara adalah sebuah perusahaan yang bergerak dalam bidang usaha penangkapan, penampungan ikan, dan industri pembekuan serta perdagangan ekspor dan impor. Perusahaan ini berdiri pada tahun 1994, pada awalnya PT. Hasil Laut Sejati ini bertempat di Tanjung Balai Asahan, awal merintis perusahaan ini belum mempunyai tempat dan masih menumpang dengan perusahaan yang lain di Tanjung Balai Asahan dan hanya mempunyai cold storage dan dua armada kapal penangkap, perusahaan ini sempat berhenti beberapa tahun bahkan sampai hampir bangkrut karena faktor keuangan pada tahun 1996, dan pada awal tahun 2000 seiring meningkatnya permintaan ekspor dan tingginya jumlah hasil tangkapan perusahaan ini bisa mendirikan sendiri bangunan perusahaan yang bertempat di Jembatan dua Barelang, Batam-Kepulauan Riau, dan perkembangan perusahaan ini semakin pesat karena di tambah ada pendanaan modal dari asing hingga mampu menambah dua cold storage dan armada kapal sebanyak sebanyak 11 unit kapal purse seine, 1 unit kapal pengangkut terhitung pada bulan Febuari 2018. Permesinan perikanan sebagai jantung dari pada kegiatan penangkapan ikan, jelas tidak bisa dipandang sebelah mata. Upaya-upaya untuk tetap menjaga kondisi mesin tetap harus diperhatikan agar aktifitas penangkapan ikan dapat berjalan dengan lancar dan sesuai dengan tujuan yang diharapkan. Perawatan serta perbaikanperbaikan terhadap komponen permesinan merupakan rutinitas yang tidak boleh diabaikan guna menunjang kondisi mesin sebagaimana disebut diatas. Salah satu kegiatan dalam perawatan mesin adalah dengan senantiasa memperhatikan kondisi sistem pelumasannya.

Pelumasan mesin dalam pengertian sempit ialah memberi minyak lumas/oli pada bagian mesin yang memerlukan. Dalam arti yang luas bukan hanya itu saja melainkan harus memilih pelumas yang tepat dan memelihara agar minyak lumas/oli selalu dalam kondisi baik di dalam mesin dan di tempat persediaan, yang dimaksud pelumas dalam kondisi baik yaitu: Kekentalannya, kebersihannya, warnanya, dan kemurniannya

Minyak pelumas adalah salah satu produk minyak bumi yang masih mengandung senyawa-senyawa aromatik dengan indek viskositas yang rendah. Hampir semua mesin-mesin dipastikan menggunakan minyak pelumas. Fungsi minyak pelumas adalah mencegah kontak langsung antara dua permukaan yang saling bergesekan. Minyak pelumas yang digunakan mempunyai jangka waktu pemakaian tertentu, tergantung dari kerja mesin, minyak pelumas merupakan sarana pokok dari suatu mesin untuk dapat beroperasi secara optimal. Dengan demikian pelumas mempunyai peranan yang besar terhadap operasi mesin, untuk dapat menentukan jenis pelumas yang tepat digunakan pada suatu sistem mesin, perlu diketahui beberapa parameter mesin yang antara lain : kondisi kerja, suhu, dan tekanan di daerah yang memerlukan pelumasan. Daerah yang bersuhu rendah tentu akan menggunakan pelumas yang lain dengan daerah yang bersuhu tinggi, demikian pula dengan daerah yang berkondisi kerja berat akan menggunakan pelumas yang lain pula dengan daerah yang berkondisi kerja ringan.

Viskositas dari suatu pelumas dipengaruhi oleh perubahan suhu dan tekanan, apabila suhu suatu pelumas meningkat, maka viskositasnya akan menurun, begitu juga sebaliknya apabila suhu suatu pelumas menurun, maka viskositasnya akan meningkat ini berarti pelumas akan mudah mengalir ketika pada suhu panas dibandingkan pada saat suhu dingin. Viskositas pada pelumas 
akan meningkat seiring meningkatnya juga tekanan yang ada di sekitar pelumas. Untuk mengetahui viskositas minyak pelumas dibutuhkan uji laboratorium berdasarkan instrumen yang mendukung pengujian sampel minyak pelumas. Karena viskositas suatu minyak pelumas dapat diketahui dengan pasti melalui pengukuran berdasarkan instrumen viscometer. Penelitian ini membahas tentang penyebab naik dan turunnya viskositas pada pelumas, zat aditif yang diperlukan untuk menambah performa Waktu penelitian dilaksanakan dari tanggal 25 November 2017 sampai dengan tanggal 01 Mei 2018 dengan lokasi penelitian di PT. Hasil Laut Sejati Pulau Nipah, Batam, Propinsi. Kepulauan Riau. Alat dan bahan yang digunakan untuk penelitian, yaitu terdiri dari alat seperti: unit mesin induk, kamera, botol sample, dan peralatan lainya.

\section{HASIL DAN PEMBAHASAN}

Berdasarkan hasil pengujian sampel minyak pelumas, penulis mengambil sampel Oli baru dan Oli sesudah di gunakan. Dimana viskositas sangat penting karena dari viskositas penulis bisa melihat indikasi awal permasalahan pada pelumas. Tujuan penulis menganalisa sampel di laboratorium untuk mengecek kondisi pelumas dan viskositas oli baru dan setelah oli tergunakan.

Hasil sampel laboratorium seperti dalam tabel 1 bahwa setelah di uji di laboratorium minyak pelumas ditemukan pada kondisi tidak normal (urgent).

a) Hasil dari uji fisik viskositas, nilai uji viskositas di oli baru 11.33 yang seharusnya pada oli normal, uji fisik viskositas di 100C untuk oli Shell Rimula R4X 15W 40 nilai ujinya 14,7 .

b) Nilai TBN (Total base number) di hasil laboratorium menunjukan 17.1 dan seharusnya di oli Shell Rimula R4X 15W 40 standar nilai TBN nya adalah 10.5. Ini bisa terindikasi kalau oli tercampur dengan oli merek lain, atau tercampur dengan zat aditif yang di luar oli, dan viskositas di bawah standar karena tercampur dengan bahan bakar.

c) Nilai Oksidasi di oli baru sangat tinggi 0.56 padahal apabila itu benar-benar oli baru seharusnya nilai Oksidasi 0 , karena belum mengalami proses operasi di mesin. Melihat jadi indikasi oli baru yang di atas kapal KM. pelumas, dan menganalisis minyak pelumas yang telah digunakan dalam waktu tertentu dengan standar SAE 15W-40. Sedangkan tujuan dari penelitian ini adalah untuk mengetahui viskositas minyak pelumas, mengetahui zat aditif yang terkandung minyak pelumas, dan menganalisis hasil pengujian laboratorium.

\section{BAHAN DAN METODE}

Sedangkan bahan-bahan yang digunaka adalah minyak pelumas baru dan bekas. Metode yang dilakukan adalah metode penelitian survey dengan mengadakan observasi langsung untuk memperoleh data dan informasi, melakukan wawancara dan pengumpulan data-data yang berkaitan selama penelitian.

Sumber Laut bisa jadi itu adalah oli bekas atau tercampur dengan oli merk lain, atau indikasi itu adalah oli palsu.

Berdasarkan hasil analisa uji sampel pelumas sebelum pemakaian, penyebab turunnya viskositas pada pelumas di KM. Sumber Laut adalah karena Oli tercampur dengan oli merk lain, tercampur dengan zat aditif yang di luar oli dan tercampurnya dengan bahan bakar. Akibat dari tercampurnya pelumas dengan bahan bakar dapat mengurangi mutu dari pelumas dan fungsi utama dari pelumas berkurang. Tindakan yang harus diambil (Action to be taken) adalah segera periksa kesesuaian identitas sampel, pastikan sampel oli baru atau bukan. Uji laboratorium ini sangat penting terhadap mesin. Baik kru kapal atau pemilik kapal, karena penggunaan oli yang tidak tepat akan berdampak buruk pada mesin.

Berdasarkan hasil pengujian minyak pelumas dengan menggunakan alat viskometer. Hasil Laboratorium oli dengan merk oli Shell Rimula R4X 15W-40 dengan jam kerja 312 jam. Dilihat dari uji fisik nilai uji Viskositasnya 11.00, turun dibawah nilai perhatian (Attention) ini bisa terindikasi mesin yang Overheat/Overload atau terlalu panas dan menyebabkan Viskositas oli menurun, dan karena tercampurnya bahan bakar yang mengakibatkan Viskositas oli turun. Dapat dilihat pada hasil laboratorium, ada bahan bakar 
dengan distilasi (fuel by diseletion) paling bawah. Menunjukan nilai uji 0,5 yang berarti menunjukan adanya kebocoran bahan bakar yang membuat viskositas oli turun.

Tabel 1. Hasil pengujian viskositas minyak pelumas baru

Table 1. Results of testing of new lubricating oil viscosity

\begin{tabular}{|c|c|c|c|c|c|}
\hline \multicolumn{6}{|c|}{ Hasil Uji Minyak Pelumas } \\
\hline \multirow{7}{*}{\multicolumn{3}{|c|}{$\begin{array}{l}\text { Laboratorium Jumlah } \\
\text { Sampling Tanggal } \\
\text { Tanggal diterima } \\
\text { Tanggal Laporan } \\
\text { Jam Minyak } \\
\text { Jam Pada Satuan } \\
\text { Ganti Minyak Pelumasl }\end{array}$}} & \multirow{7}{*}{$\begin{array}{c}\text { OJ03472/UO/18 } \\
01-04-2018 \\
23-05-2018 \\
28-05-2018 \\
\text { NEW OIL }\end{array}$} & \multirow{2}{*}{\multicolumn{2}{|c|}{ Keseluruhan Analisis Hasi }} \\
\hline & & & & & \\
\hline & & & & & \\
\hline & & & & & \\
\hline & & & & & \\
\hline & & & & & \\
\hline & & & & & \\
\hline Uji Fisik & Satuan & Metode & Uji Nilai & Perhatian & Mendesak \\
\hline \multirow{2}{*}{$\begin{array}{l}\text { Visc @ 40C } \\
\text { Visc @ 100C }\end{array}$} & $\mathrm{cSt}$ & ASTM D445-12 & & $80 / 120$ & $72 / 132$ \\
\hline & $\mathrm{cSt}$ & ASTM D445-12 & $11.33 / \mathrm{C}$ & $12.5 / 16.3$ & $11.25 / 17.93$ \\
\hline TAN & $\mathrm{Mg} \mathrm{KOH} / \mathrm{g}$ & ASTM D974-12 & & & \\
\hline TBN & $\mathrm{Mg} \mathrm{KOH} / \mathrm{g}$ & ASTM D2896-11 & 17.1 & 6.05 & 4.4 \\
\hline \multicolumn{6}{|l|}{ Logam Aditif } \\
\hline Magnesium (Mg) & ppm & ASTM D5185-13e1 & & & \\
\hline Kalsium $(\mathrm{Ca})$ & ppm & ASTM D5185-13e1 & & & \\
\hline Zinc $(\mathrm{Zn})$ & $\mathrm{ppm}$ & ASTM D5185-13e1 & & & \\
\hline \multicolumn{6}{|l|}{ Kontaminan } \\
\hline Natrium (Na) & ppm & ASTM D5185-13e1 & 9 & 35 & 50 \\
\hline Silicon $(\mathrm{Si})$ & ppm & ASTM D5185-13e1 & 5 & 15 & 25 \\
\hline \multicolumn{6}{|l|}{ Kenakan Logam } \\
\hline Besi (Fe) & $\mathrm{ppm}$ & ASTM D5185-13e1 & 5 & 50 & 100 \\
\hline Tembaga $(\mathrm{Cu})$ & ppm & ASTM D5185-13e1 & 1 & 25 & 35 \\
\hline Alumunium $(\mathrm{Al})$ & ppm & ASTM D5185-13e1 & 2 & 18 & 25 \\
\hline Chromium (Cr) & $\mathrm{ppm}$ & ASTM D5185-13e1 & $<1$ & 10 & 15 \\
\hline Nikel (Ni) & ppm & ASTM D5185-13e1 & $<1$ & 5 & 10 \\
\hline Tin $(\mathrm{Sn})$ & ppm & ASTM D5185-13e1 & $<1$ & 10 & 20 \\
\hline Memimpin $(\mathrm{Pb})$ & $\mathrm{ppm}$ & ASTM D5185-13e1 & $<1$ & 35 & 50 \\
\hline \multicolumn{6}{|l|}{ FTIR } \\
\hline Jelaga & $\mathrm{Abs} / 0.1 \mathrm{~mm}$ & ASTM E2412-10 & 0.02 & 0.6 & 0.8 \\
\hline Oksidasi & $\mathrm{Abs} / 0.1 \mathrm{~mm}$ & ASTM E2412-10 & $0.56 / \mathrm{C}$ & 0.3 & 0.5 \\
\hline Nitrasi & $\mathrm{Abs} / 0.1 \mathrm{~mm}$ & ASTM E2412-10 & 0.14 & 0.3 & 0.5 \\
\hline Sulfation & $\mathrm{Abs} / 0.1 \mathrm{~mm}$ & ASTM E2412-10 & 0.11 & 0.3 & 0.5 \\
\hline Fuel Pengenceran *) & $\%$ & ASTM E2412-10 & & 2 & 3 \\
\hline Kandungan air *) & $\%$ & ASTM E2412-10 & 0 & 0.1 & 0.2 \\
\hline Glycol *) & $\%$ & ASTM E2412-10 & 0 & 2 & 3 \\
\hline \multicolumn{6}{|l|}{ LAIN } \\
\hline Bahan bakar dengan Destilasi & $\% \mathrm{~V} / \mathrm{v}$ & ASTM D322-12 & 1 & 2 & 3 \\
\hline PQ Indeks *) & - & PQ Analyzer & 1 & 16 & 21 \\
\hline
\end{tabular}

Sumber: Lube and Fuel Laboratory Consultant PT. Petrolab Services, 2018.

TBN (Total base number) sebelumnya adalah dengan nilai uji TBN 17.1, dan ketika oli digunakan nilai uji TBN menjadi 15.03. Itu normal karena TBN menetralisir asam sulfur di bahan bakar. Lalu dilihat ada kontaminasi silicon yang

Copyright @ JKPT Juni 2018

Kajian Penerapan Viskositas Minyak Pelumas

berasal dari kotoran dari luar mesin. Berdasarkan hasil analisa uji sampel pelumas sesudah digunakan, penyebab turunnya viskositas pada pelumas (Source of Abnormality) mesin utama pada di KM. Sumber Laut adalah: (1) dikarenakan 
temperatur mesin terlalu panas (overheat), Oli semakin lama dipanasin semakin cair. Yaitu karena terlalu panasnya, kekentalan oli menjadi cair sehingga kekentalannya menurun; (2) terkontaminasi/ tercampurnya pelumas dengan bahan bakar. Oli tercampur bahan bakar semakin encer; (3) adanya kebocoran bahan bakar (Fuel by distillation) $0.5 \%$. sedangka akibat dari turunnya viskositas pada pelumas adalah: (1) mengurangi mutu dari pelumas; (2) fungsi utama dari pelumas berkurang; (3) dapat merusak material pada mesin. Kemudian langkah-langkah yang harus dilakukan (Action to be taken) adalah: (1) segera periksa penyebab rendahnya nilai viskositas; (2) periksa kemungkinan terjadi overheat/overload, (3) cek oil level; (4) perhatikan masa pakai pelumas; (5) cek kemungkinan kebocoran fuel system; (6) jika pelumas belum diganti, disarankan melakukan penggantian pelumas; (7) resampling 250 jam berikutnya untuk monitoring.

Tabel 2. Hasil pengujian minyak pelumas sesudah digunakan

Table 2. Test results for lubricating oil after use

\begin{tabular}{|c|c|c|c|c|c|}
\hline \multicolumn{6}{|c|}{ Hasil Uji Minyak Pelumas } \\
\hline $\begin{array}{l}\text { Laboratorium Jumlah } \\
\text { Sampling Tanggal } \\
\text { Tanggal diterima } \\
\text { Tanggal Laporan } \\
\text { Jam Minyak } \\
\text { Jam Pada Satuan } \\
\text { Ganti Oil }\end{array}$ & & & $\begin{array}{c}\text { OJ03473/UO/18 } \\
11-04-2018 \\
23-05-2018 \\
28-05-2018 \\
312\end{array}$ & \multicolumn{2}{|c|}{ Keseluruhan Analisis Hasil } \\
\hline Uji Fisik & Satuan & Metode & Uji Nilai & Perhatian & Mendesak \\
\hline $\begin{array}{l}\text { Visc @ 40C } \\
\text { Visc @ 100C }\end{array}$ & $\begin{array}{l}\mathrm{cSt} \\
\mathrm{cSt}\end{array}$ & $\begin{array}{l}\text { ASTM D445-12 } \\
\text { ASTM D445-12 }\end{array}$ & $11.00 / \mathrm{C}$ & $\begin{array}{c}80 / 120 \\
12.5 / 16.3\end{array}$ & $\begin{array}{c}72 / 132 \\
11.25 / 17.93\end{array}$ \\
\hline TAN & $\mathrm{Mg} \mathrm{KOH} / \mathrm{g}$ & ASTM D974-12 & & & \\
\hline TBN & $\mathrm{Mg} \mathrm{KOH} / \mathrm{g}$ & ASTM D2896-11 & 15.03 & 6.05 & 4.4 \\
\hline \multicolumn{6}{|l|}{ Logam Aditif } \\
\hline Magnesium (Mg) & ppm & ASTM D5185-13e1 & & & \\
\hline Kalsium $(\mathrm{Ca})$ & $\mathrm{ppm}$ & ASTM D5185-13e1 & & & \\
\hline Zinc (Zn) & ppm & ASTM D5185-13e1 & & & \\
\hline \multicolumn{6}{|l|}{ Kontaminan } \\
\hline Natrium $(\mathrm{Na})$ & ppm & ASTM D5185-13e1 & 16 & 35 & 50 \\
\hline Silicon $(\mathrm{Si})$ & ppm & ASTM D5185-13e1 & $15 / \mathrm{B}$ & 15 & 25 \\
\hline \multicolumn{6}{|l|}{ Kenakan Logam } \\
\hline Besi (Fe) & $\mathrm{ppm}$ & ASTM D5185-13e1 & 20 & 50 & 100 \\
\hline Tembaga $(\mathrm{Cu})$ & $\mathrm{ppm}$ & ASTM D5185-13e1 & 3 & 25 & 35 \\
\hline Alumunium $(\mathrm{Al})$ & $\mathrm{ppm}$ & ASTM D5185-13e1 & 4 & 18 & 25 \\
\hline Chromium $(\mathrm{Cr})$ & ppm & ASTM D5185-13e1 & 2 & 10 & 15 \\
\hline Nikel (Ni) & ppm & ASTM D5185-13e1 & $<1$ & 5 & 10 \\
\hline $\operatorname{Tin}(\mathrm{Sn})$ & $\mathrm{ppm}$ & ASTM D5185-13e1 & 1 & 10 & 20 \\
\hline Memimpin $(\mathrm{Pb})$ & $\mathrm{ppm}$ & ASTM D5185-13e1 & 1 & 35 & 50 \\
\hline \multicolumn{6}{|l|}{ FTIR } \\
\hline Jelaga & $\mathrm{Abs} / 0.1 \mathrm{~mm}$ & ASTM E2412-10 & 0.23 & 0.6 & 0.8 \\
\hline Oksidasi & $\mathrm{Abs} / 0.1 \mathrm{~mm}$ & ASTM E2412-10 & 0.15 & 0.3 & 0.5 \\
\hline Nitrasi & $\mathrm{Abs} / 0.1 \mathrm{~mm}$ & ASTM E2412-10 & 0.15 & 0.3 & 0.5 \\
\hline Sulfation & $\mathrm{Abs} / 0.1 \mathrm{~mm}$ & ASTM E2412-10 & 0.09 & 0.3 & 0.5 \\
\hline Fuel Pengenceran *) & $\%$ & ASTM E2412-10 & & 2 & 3 \\
\hline Kandungan air *) & $\%$ & ASTM E2412-10 & 0 & 0.1 & 0.2 \\
\hline Glycol *) & $\%$ & ASTM E2412-10 & 0 & 2 & 3 \\
\hline \multicolumn{6}{|l|}{ LAIN } \\
\hline Bahan bakar dengan Destilasi & $\% \mathrm{~V} / \mathrm{v}$ & ASTM D322-12 & 0.5 & 2 & 3 \\
\hline PQ Indeks *) & - & PQ Analyzer & 14 & 16 & 21 \\
\hline
\end{tabular}

Copyright (C) JKPT Juni 2018

Kajian Penerapan Viskositas Minyak Pelumas ........Alirejo, et.al 
Berdasarkan hasil analisa pengujian sampel pelumas Shell Rimula R4X 15W 40, akibat dari turunnya viskositas pada pelumas KM. Sumber Laut dapat mengurangi mutu dari pelumas, fungsi utama dari pelumas berkurang dan dapat merusak material pada mesin. Maka dari itu perlu dengan adanya penambahan zat aditif pada pelumas yang di gunakan di KM. Sumber Laut, tujuan berguna untuk meningkatkan kinerja suatu pelumas seperti yang di harapkan. Dengan adanya Aditif ini dapat menentukan mutu pelumas yang akan digunakan karena dapat merubah sifat kimia maupun sifat fisik dari oli. Tujuan dari aditif itu sendiri untuk campuran pelumas yaitu untuk melindungi dan memperbaiki mutu pelumas, melindungi kerusakan mesin terhadap produk-produk hasil pembakaran dan memperbaiki sifat suatu pelumas atau memberikan sifat baru terhadap sifat pelumas yang sesuai dengan penggunaannya.

Mengenai zat aditif yang di perlukan untuk menambah performa pelumas mesin adalah sebagai berikut :

a) Total Base Number (TBN), zat aditif yang di tambahkan pada pelumas untuk menetralisir asam sulfat yang terdapat akibat proses pembakaran.

b) Anti Foam, dengan adanya penambahan aditif ini untuk mencegah terbentuknya busa pada pelumas. Pembusaan pada minyak lumas terjadi bila minyak lumas tersebut dikenakan udara sehingga timbul gelembung-gelembung didalamnya (Foaming). Gelembunggelembung foam ini sangat mengganggu jalannya operasi mesin pada kondisi tertentu sebab akan menyebabkan gagalnya sistem kerja dari bearing kecuali jika gelembunggelembung ini cepat hilang. Untuk mencegah terbentuknya foam yang berlebihan, maka pada minyak lumas ditambahkan Anti Foam.

c) Anti Rust, dengan adanya penambahan zat aditif ini pada pelumas guna mencegah terjadinya karat pada bagian logam yang berhubungan dengan pelumas.

d) Anti Oksidant, dengan adanya penambahan zat aditif ini guna mencegah terjadinya proses oksidasi pada molekul pelumas. Pada pelumas yang viskositasnya terlalu rendah akan menghasilkan panas yang berlebihan yang dapat menghasilkan oil oxidation (Oksidasi Pelumas). Jadi untuk menghindari oksidasi tersebut, pada pelumas ditambahkan aditif Oxidation Inhibitors, sebab bila oksidasi ini tidak dicegah akan berbentuk lumpur (sludge) dan pernis (varnish).

e) Anti Wear, adanya penambahan aditif ini guna untuk mencegah gesekan dan keausan pada permukaan mesin.

f) Deterjen, penambahan aditif adalah berfungsi sebagai pembersih dan penetralisir zat-zat yang berbahaya, seperti halnya indikasi pada hasil analisa sampel pelumas. Adanya pelumas tercampur bahan bakar, ada kontaminasi silicon yang berasal dari kotoran dari luar mesin, tercampur dengan zat aditif yang di luar oli. Dan membentuk lapisan pelindung pada permukaan logam, mencegah endapan, mengurangi timbulnya deposit, mengendalikan korosi serta membersihkan karbon sisa pembakaran agar karbon tidak menempel di komponen mesin.

Berdasarkan hasil sampel pengujian minyak pelumas baru sebagai berikut :

a) Uji fisik Viskositas minyak pelumas dengan temperatur $100^{\circ} \mathrm{C}$, dengan metode American Society for Testing and Materials (ASTM D445-12) di peroleh hasil uji nilai 11.33.

b) Uji fisik Total base number (TBN) dengan metode ASTM D2896-11 di peroleh hasil uji nilai 17.1.

c) Uji Kontaminan dengan metode ASTM D5185-13e1 di peroleh hasil uji Natrium (Na) uji nilai 9. Hasil uji Silicon (Si) uji nilai 5.

d) Uji Unsur Logam dengan metode ASTM D5185-13e1 di peroleh hasil uji Besi (Fe) uji nilai 5 , hasil uji Tembaga $(\mathrm{Cu})$ uji nilai 1 , hasil uji Alumunium (Al) uji nilai 2, hasil uji Chromium $(\mathrm{Cr})$ uji nilai $<1$, hasil uji Nikel (Ni) uji nilai $<1$, hasil uji Tin $(\mathrm{Sn})$ uji nilai $<1$, dan hasil uji Memimpin $(\mathrm{Pb})$ uji nilai $<1$.

e) Uji FTIR dengan metode ASTM E2412-10 di peroleh hasil uji Jelaga uji nilai 0.02, hasil uji Oksidasi uji nilai 0.56, hasil uji Nitrasi uji nilai 0.14 , hasil uji Sulfation uji nilai 0.11 , hasil uji kandungan air uji nilai 0 , hasil uji Glycol uji nilai 0 .

f) Uji Lain dengan metode ASTM D322-12 di peroleh hasil uji Bahan bakar dengan Destilasi uji nilai 1, hasil uji PQ Indeks dengan metode PQ Analyzer uji nilai 1. 
Sedangkan dari hasil pengujian sampel minyak pelumas yang sudah digunakan (312 jam kerja mesin) diperoleh data sebagai berikut:

a) Uji Fisik Viskositas minyak pelumas dengan temperatur $100^{\circ} \mathrm{C}$, dengan metode ASTM D445-12 di peroleh hasil uji nilai 11.00. Uji fisik TBN dengan metode ASTM D2896-11 di peroleh hasil uji nilai 15.03;

b) Uji Kontaminan dengan metode ASTM D5185-13e1 di peroleh hasil uji Natrium (Na) uji nilai 16. Hasil uji Silicon (Si) uji nilai 15;

c) Uji Unsur Logam dengan metode ASTM D5185-13e1 di peroleh hasil uji Besi (Fe) uji nilai 20 , hasil uji Tembaga $(\mathrm{Cu})$ uji nilai 3 , hasil uji Alumunium (Al) uji nilai 4, hasil uji Chromium (Cr) uji nilai 2, hasil uji Nikel (Ni) uji nilai $<1$, hasil uji Tin (Sn) uji nilai 1, dan hasil uji Memimpin $(\mathrm{Pb})$ uji nilai 1 ;

d) Uji FTIR dengan metode ASTM E2412-10 di peroleh hasil uji Jelaga uji nilai 0.23 , hasil uji Oksidasi uji nilai 0.15, hasil uji Nitrasi uji nilai 0.15 , hasil uji Sulfation uji nilai 0.09, hasil uji kandungan air uji nilai 0 , hasil uji Glycol uji nilai 0;

e) Uji Lain dengan metode ASTM D322-12 di peroleh hasil uji Bahan bakar dengan Destilasi uji nilai 0.5, hasil uji PQ Indeks dengan metode PQ Analyzer uji nilai 14.

\section{KESIMPULAN}

Viskositas pelumas sangat berperan penting dalam sistem pelumasan, karena dari viskositas bisa diketahui indikasi awal permasalahan pada pelumas. Turunnya viskositas pelumas di KM. Sumber Laut akan berdampak langsung pada sistem mesin keseluruhan. Penyebab turunnya viskositas pelumas pada KM. Sumber Laut yaitu tercampurnya dengan minyak pelumas merk lain, zat aditif yang diluar oli, tercampur dengan bahan bakar, dikarenakan temperatur mesin terlalu panas, terkontaminasi pelumas dengan bahan bakar dan adanya kebocoran bahan bakar. Akibat dari turunnya viskositas pada pelumas adalah dapat mengurangi mutu dari pelumas, fungsi utama dari pelumas berkurang dan dapat merusak material/komponen pada mesin.

Penambahan zat aditif pada pelumas dengan tujuan untuk meningkatkan kinerja suatu pelumas seperti yang diharapkan, karena dapat merubah sifat kimia maupun sifat fisik dari oli. Dengan adanya aditif ini yaitu untuk memperbaiki mutu pelumas, melindungi kerusakan mesin terhadap produkproduk hasil pembakaran dan memperbaiki sifat suatu pelumas atau memberikan sifat baru terhadap sifat pelumas yang sesuai dengan penggunaannya. Pengujian minyak pelumas di laboratorium sangat penting terhadap mesin. Karena dari hasil uji laboratorium dapat mengetahui indikasi permasalahan pada pelumas di KM. Sumber Laut, masa pemakaian pelumas, pelumas masih layak dipakai atau tidak, masa pergantian pelumas, dan penggunaan oli yang tidak tepat akan berdampak buruk pada mesin.

Sebaiknya di lakukan pengambilan sampel pelumas secara berkala agar dapat mengetahui kondisi pelumas pada mesin utama, masa pakai pelumas dan masa pergantian minyak pelumas serta resampling 250 jam berikutnya untuk monitoring. 


\section{DAFTAR PUSTAKA}

Akrom, D. (2009). Lub oil, Minyak Pelumas. Power plant. PT. Toyota-Astra Motor. 1980. Toyota Materi Pelajaran Engine Group. Jakarta

Arisandi M., Darmanto dan T. Priangkoso. (2012). Analisa Pengaruh Bahan Dasar Pelumas Terhadap Viskositas Pelumas dan Konsumsi Bahan Bakar. Jurnal Momentum. Vol. 8. No. 1

Arismunandar, Wiranto. (1981). Penyegaran Udara, PT. Pradnya Paramita. Jakarta.

Arismunandar, W. dan K. Tsuda. (2008). Motor Diesel Putaran Tinggi. Pradnya Paramita: Jakarta

Arismunandar, Wiranto., (2005), Penggerak Mula Motor Bakar Torak, Institut Teknologi Bandung, Bandung.

Ariyanti, E.S. dan Agus, M, (2010), "Otomasasi Pengukuran Koefisien Viskositas Zat Cair Menggunkan Gelombang Ultrasonik," Jurnal Neutrino, vol. 2, No. 27 Agustus 2015.

Bernando, B. (2015). “Pengukuran Kekentalan Zat (Viskositas)”. Fakultas Sains dan Teknologi Program Studi Fisika Universitas Islam Negeri Sunan Gunung Djati. Bandung.

Bernard, J.Hamrock. (2004). "Fundamentals of Fluid Film Lubrication" Second Edition. USA. Marcel Dekker, Inc.

Bird, T. (1994). Kimia Fisik untuk Universitas. Jakarta: Gramedia Pustaka Utama.

BM. Surbakty, (1985). Motor Bakar. Mutiaraso.

E. Karyanto, (1985). Motor Diesel. Jakarta.

Halliday dan Resnick, (2000), “Fisika," Erlangga, Jakarta.

Hidayat, B. (2008). Teknik Perawatan, Pemeliharaan dan Reparasi Sepeda Motor. Yogyakarta: Absolut.

Jones, F. R. (1963). Farm Gas Engine and Tractors. Mc Graw Hill Book Company, Inc. New York.

Lumbantoruan, P, \& Yulianti, E. (2016). Pengaruh suhu terhadap Viskositas Minyak Pelumas (Oli). Jurnal Sainmatika Vol. 13. No. 2. ISSN: 1829-586X

Maleev. V.L. (1995). Operasi Dan Pemeliharaan Mesin Diesel, terj. Priambodo bambang, Erlangga, Jakarta.
Nugroho, S, R. \& Sunarno, H.(2012). Identitas Fisis Viskositas Oli Mesin Kendaraan Bermotor Terhadap Fungsi Suhu dengan Menggunakan Laser Helium Neon. Jurnal Sains dan Seni Volume 1.

Olson, R. (1993). Dasar-Dasar Mekanika Fluida Teknik; edisi Kelima. PT. Gramedia Pustaka Utama. Jakarta.

https://artikel-teknologi.com/macam-macam-zataditif-pelumas-oli/. Diakses tanggal 10 Januari 2018, Pukul 22.00 WIB.

Pudyasmara, A. (2006). Perencanaan dan Pembuatan Viscometer menggunakan pemutar. Jurusan Fisika Univ. Brawijaya. Malang

Rahman, Jhonni. (2014). Analisa Pengaruh Viskositas Pelumas terhadap Jumlah Putaran dan Daya. Jurnal RAT Vol 3. No. 1. ISSN: 2252-9608.

Sani, (2010). Pengaruh Pelarut Phenol pada Reklamsi Minyak Pelumas. Unesa University Press. Diakses dari http://eprints.upnjatim.ac.id/3002 /2/Minyak_Pelumas. pdf pada tanggal $3 \mathrm{Mei}$ 2015.

Soenarta, Nakoela. (1985). "Motor serbaguna / Nakoela Soenarta, Shoichi Furuhama"

Sudarmaji. (2007). Analisa Gangguan dan Cara Mengatasi Sistem Pelumasan Mazda MR. Semarang: jurusan Teknik Mesin Universitas Negeri Semarang.

Sujanto. (1983). Pesawat Kapal 2. Jakarta.

Yanmar Diesel. (1980). Mesin Diesel Yanmar Buku Petunjuk 2. PT. Yanmar Indonesia, Jakarta.

Copyright (C) JKPT Juni 2018

Kajian Penerapan Viskositas Minyak Pelumas ........Alirejo, et.al 